Policy \& Politics $•$ vol $46 \cdot$ no $2 \cdot 255-72 \cdot$ (C) Policy Press 2018

Print ISSN $03055736 \cdot$ Online ISSN $14708442 \cdot$ https://doi.org/10.1332/030557318X15230059735521

Accepted for publication 02 March 2018 • First published online 16 April 2018

This article is distributed under the terms of the Creative Commons Attribution 4.0 license (http://creativecommons.org/licenses/by/4.0/) which permits adaptation, alteration, reproduction and distribution without further permission provided the

original work is attributed. The derivative works do not need to be licensed on the same terms.

SPECIAL ISSUE • Practical lessons from policy theories

\title{
article
}

\section{The lessons of policy learning: types, triggers, hindrances and pathologies ${ }^{1}$}

\author{
Claire A Dunlop, c.a.dunlop@exeter.ac.uk \\ University of Exeter, UK \\ Claudio M Radaelli, c.radaelli@exeter.ac.uk \\ University of Exeter, UK
}

Policy learning is an attractive proposition, but who learns and for what purposes? Can we learn the wrong lesson? And why do so many attempts to learn what works often fail? In this article, we provide three lessons. First, there are four different modes in which constellations of actors learn. Hence our propositions about learning are conditional on which of the four contexts we refer to. Second, policy learning does not just happen; there are specific hindrances and triggers. Thus, learning can be facilitated by knowing the mechanisms to activate and the likely obstacles. Third, learning itself is a conditional final aim: although the official aspiration of public organisations and politicians is to improve on public policy, policy learning can also be dysfunctional - for an organisation, a policy, a constellation of actors or even democracy.

key words policy context $\cdot$ policy failure $\cdot$ policy learning $\cdot$ policy transfer $\cdot$ translational reach

To cite this article: Dunlop, C.A. and Radaelli, C.M. (2018) The lessons of policy learning: types, triggers, hindrances and pathologies, Policy \& Politics, vol 46, no 2, 255-72,

DOI: $10.1332 / 030557318 \times 15230059735521$

\section{Introduction}

The literature on policy learning has generated a huge amount of heat (and some light) producing policy learning taxonomies, concepts and methods, yet the efforts to demonstrate why we should think about policy processes in terms of learning have been rare and mostly in the past (Dunlop, Radaelli and Trein, 2018). Additionally, policy learning has progressed in different sub-fields, such as the study of diffusion, transfer, individual and collective learning, social learning, and knowledge utilisation (see the family tree of learning in Dunlop, Radaelli and Trein, 2018; and the fragmentation in sub-fields portrayed in Goyal and Howlett, 2018). This has 
discouraged the tasks of communicating, comparing and combining insights that, the editors of this special issue remind us, are fundamental to translate research to a wider audience, avoiding jargon and obfuscation.

We offer this article to both an audience of academics and to actors involved in policy-processes, be they elected politicians, public managers, activists or pressure groups. We address the academic audience made up of specialists in policy analysis by arguing that the quality of our findings should be judged in terms of 'translation reach'. We set out to show how we can combine and integrate research on learning so that it can be translated to a wider audience of social scientists looking for cumulative findings, typical lessons, concepts that travel across fields.

The concept of 'wider audience' means, however, that a useful assemblage, synthesis and communication of findings should also assist social scientists in carrying a conversation with those who are directly involved or affected by policy processes. Our central proposition is that these two readerships (social scientists and practitioners) can be combined if we fine-tune our effort to maximise the reach of translation around exemplary lessons. Thus, we answer the following questions: what are the lessons of thinking about policy processes in terms of learning? What are their triggers and hindrances? What can go wrong with learning, that is, what are the pathologies? Answering these particular questions shows to social scientists the value and explanatory leverage of drawing on learning theory to analyse public policy. But it also points practitioners towards usable knowledge: lessons that can be applied to real-world policy processes. This particular focus brings us close to another important goal of the special issue: to bridge the theory-practice divide.

Of course, to translate theory into practice does not mean to supply a menu of policy recommendations for concrete problems and cases. Different actors need diverse translations. Learning is the process of updating beliefs about public policy. This can of course refer to beliefs on how to make policy more efficient, legitimate, democratic. It can also, however, mean learning how to use public policy to win consensus, to promote one's strategy, to humiliate the opposition - without necessarily improving on efficiency or effectiveness. Thus, there are too many practical translations of learning into recommendations, unless we answer the question 'learning for whom and what purposes'.

Indeed, a recommendation may empower an actor but disempower another. Rather than recommendations, theory-driven lessons, based on significant accumulation of findings, show typical ways in which theory can become relevant. They inspire large audiences rather than directing a specific actor towards a strategy. They frame reality in a way that is creative and illuminating.

This stance, finally, allows us to reconnect policy learning with the ambition of the founding studies: Karl Deutsch, Herbert Simon and Charles Lindblom, were inspired by theories that would produce practical insights. In John Dewey's pragmatism, education, policy and the publics are profoundly related. Dewey's 1927 classic The Public and its Problems, reprinted in 2012, concerned engaging a public distracted and uninterested in public policy problems with the essence of democracy - a prophecy of the current mood of anti-politics. Dewey's utopia was to turn the Great Society into the Great Community (Dewey, 2012: 141). To achieve this, he even thought of mobilising the arts to draw the attention of the public towards the assimilation of 'accurate investigation' (Dewey, 2012: 140). Of course, the founding father of policy inquiry, Harold Lasswell, was aware of Dewey's lessons about bridging the gap between 
academic knowledge and society: ' $[\mathrm{O}]$ ne thing Lasswell learned from the pragmatists, and Dewey in particular, was that inquiry requires community' (Torgerson, 1992: 231).

Given this, we do not need additional motivation to explore the lessons of learning in public policy. Our analysis will be selective. We, and others, have produced reviews of the literature (Dunlop and Radaelli, 2013; Heikkila and Gerlak, 2013; Moyson, Scholten and Weible, 2017). Here, instead of drawing on a particular method to extract findings, we illustrate this with examples rather than covering a broad range of the field. We will make use of Dunlop and Radaelli (2013) more than other reviews because this is a concept-driven analysis of a vast number of empirical studies (our initial population was 833 articles) and therefore suits our purpose of combining, integrating and assembling the field into a limited number of clear propositions.

One way to navigate our contribution is the following: the features, triggers, hindrances and pathologies of learning depend on the policy process context in which actors interact: are the policy actors engaged with bargaining or are they trying to understand what works on the basis of science and evidence? Are they finding solutions within a pre-established hierarchy or rules and procedures? Or, instead, is this a policy process with the main goal of fostering participation? The 'tone' of the policy process shapes the style and nature of learning.

Our first lesson is therefore that learning has different qualities and logics depending on this tone. We will refer to four process-related contexts: epistemic (or knowledgedriven), reflexivity, bargaining and compliance with hierarchy. The second lesson is that learning has its own triggers and hindrances. It does not simply happen. The third lesson concerns dysfunctional learning - learning that is 'bad'. The question 'bad for whom, or for what?' allows multiple answers. Learning can be 'bad' for the organisation in question, or because it violates some normative standards like pluralism, accountability, or legitimacy. Finally, we conclude with what this type of research agenda can deliver to social scientists and practitioners.

\section{Lesson 1: Learning has different qualities}

Let us start again from our definition of learning as 'the updating of beliefs based on lived or witnessed experiences, analysis or social interaction' (Dunlop and Radaelli, 2013: 599). It follows that policy learning is about how knowledge that comes from these experiences, analysis and social interaction is considered and acted upon by policy actors. This centrality of the process of knowledge acquisition and belief updates reveals an important practical insight: learning may be unintentional, but it does not occur randomly - not all policy processes carry the same probability of producing learning outcomes. Thus, any answer to the question 'why does learning happen?' requires a specification of the contexts by which learning outcomes are facilitated. We argue that social scientists can communicate more effectively and more widely if they abandon an exclusive focus on learning and open their peripheral vision to these contexts. This is where our analysis aids communication among ourselves: university-based researchers and social scientists in general. Let us see why and how.

A vast literature on modes of governance and decisions in public policy (Dente, 2014) and learning types (Dunlop and Radaelli, 2013) has pinned down four predominant contexts in which policy decisions are made. These four contexts are hierarchy, bargaining, reflexivity and finally the expert-driven or epistemic. How do actors, problems, interactions fall into one category or the other? This can be the 
result of institutional choice - for example the decision to create an independent regulator. But often the same policy domain (for example, environment, housing, transportation) manages decisions in different contexts, depending on the concrete issue at stake and how actors are socially perceived as legitimate and knowledgeable. Two dimensions matter, then. One is uncertainty or issue tractability (Jenkins-Smith, 1990) and the other is the certification of actors associated with the issue (McAdam et al, 2001).

Uncertainty is low when there are ways to find a solution to a policy problem, although these ways may be costly, require a lot of evidence and time, and so on. We know how to govern the quantity of money in a country and to collect data on public expenditure in a number of policy domains. But, we do not have established ways to build regulatory budgets. Yet another set of problems exhibit radical uncertainty. The latter results in either reliance on epistemic experts or being opened up to widespread social debate. And here, we see that the social perception of actors matters. At a given time and in a given society, some actors are perceived as competent, technically skilled, independent, or all of these. That's the concept of social certification. Institutional choice may nudge social perception, for example by allocating certain powers to an independent regulator or level of governance. More generally though, we can think of all cases when a socially certified actor (institutional or not) enjoys a privileged position in the decisional context. Hence, expert groups, courts, regulators, or standard setting bodies may possess such certification. Where an issue lacks an agreed set of 'go-to' actors, policy participants are plural. Just how plural depends on the level of issue tractability. When this is high we have interest-driven actors; where both tractability and certification are low we have the most plural and social of policy arenas. Taken together, these two dimensions provide the policy-making contexts along which we situate our analysis of learning (see Figure 1).

Figure 1: Learning in decision-making contexts

PROBLEM TRACTABILITY

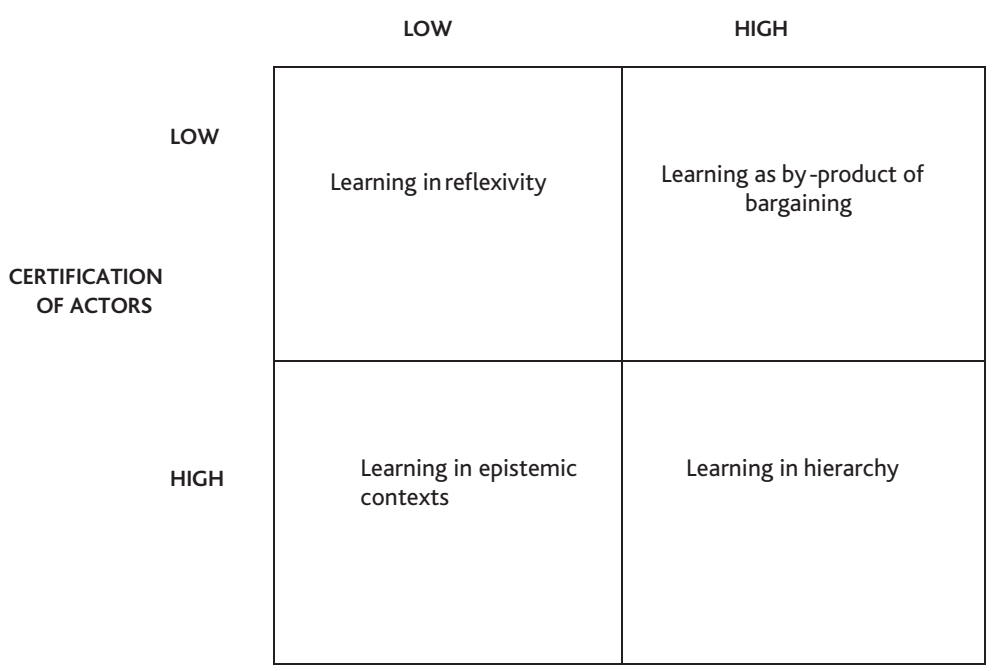

Source: Adapted from Dunlop and Radaelli, (2013, Figure 1: 603) 


\section{Learning epistemically}

Recall that in epistemic contexts there is high uncertainty: actors need to learn. When this is coupled with the existence of an authoritative body of knowledge and experts who are willing and able to interact with policy-makers and take a proper role in the policy process, for example by sitting on statutory consultative bodies, we have conditions that facilitate the transmission of problem-solving ideas. With caution, we can use the metaphor of teaching in the sense that the expert brings to the decision-making table evidence that effectively mitigates uncertainty.

How the lesson is understood or manipulated, and whether it is the right lesson to learn, is another question. Indeed, a necessary condition for successful learning is that experts must have authoritative knowledge which is policy-relevant. Consider Peter M Haas's (1990) landmark case study, United Nations (UN) decision-makers learned that the Mediterranean needed to be and could be 'saved' because the epistemic community had both exclusive access to specialist knowledge and had a credible policy plan that made the knowledge real to decision-makers. Where experts are politically ignorant, the rejection of scientific knowledge often follows (see the cases of the EU and hormone growth promoters (Dunlop, 2010, 2017c) and the difficult relationship between economists and the European Commission in the early days of EU corporate tax policy (Radaelli, 1997).

We can add to this. The most skilled teachers have more than just cognitive authority. They have the soft skills - notably, communication, leadership and entrepreneurship - to hold the attention of powerful elites (Cross, 2013; Dunlop, 2014: 216-17). Boehmer-Christiansen's (1994) work on the early years of the Intergovernmental Panel on Climate Change (IPCC) highlights the role of the panel chair - Bert Bolin - and his charismatic authority which was, in part, responsible for the step-change in learning on carbon emissions by governments in the 1990s.

Further, to absorb new knowledge, decision-makers must be in a 'ready to learn' state. In the conventional classroom, part of the teacher's role is to baseline their students to get a sense of their readiness: emotionally, physically, experientially and in terms of their knowledge (Novak and Gowin, 1984). In the policy arena, we think more in terms of how ready the system is to take on board new information. Here, the teaching mechanism is at its most potent where experts are willing and able to accommodate the often erratic and unpredictable timelines of policy-making.

What is being learned, and what is it good for? In an ideal typical manifestation, teaching mechanisms shed light on cause-and-effect relationships and how available evidence can be linked to desired policy outcomes. Of course, this is the world of evidence-based policy-making (EBPM) (Nutley et al, 2007) marked by the 'intended use by intended users' of science (Patton, 1997). Though (rightly) criticised as overlyfunctional (Cartwright and Hardie, 2012) and even at times mythological (Boswell, 2017), at the very least EBPM does afford a reduction in uncertainty. Moreover, this type of learning forces a forensic examination (if not always justification) of the logic and content of policies, and how these link to outputs (as opposed to focusing only on outcomes). 


\section{Learning from reflection}

To approach learning in the context of reflection, think of dialogue. At the level of policy-sectors, this context triggers learning if there is a predisposition to listen to what the others have to say and to re-consider one's preferences. At the macro level of society, this is Dewey's utopia of the Great Society turning into the Great Community. Today, this type of learning is embedded in several instruments for policy choice, such as participatory policy analysis, experimental governance, deliberative polling and citizens' juries. But, dialogue doesn't just 'happen' and 'function' under any condition.

Radical uncertainty and the absence of a predominant actor mean this: we all know pretty much nothing (radical uncertainty), therefore we are likely to engage in public policy by blending our individual bits and pieces of incomplete evidence/ experience with arguments and values (Majone, 1989). This makes reason and social consensus possible (Habermas, 1984). Here, the 'how' of learning is more pertinent than the 'what' (Freeman, 2006).

Thus, to generate learning we need force-free deliberations involving a wide range of social actors of myriad backgrounds who bring a range of codified and uncodified knowledge types to bear on debate. Yet, for dialogue to deliver learning results, these debates must be convened in some way such as public engagement technologies. Deliberative tools are the most open allowing iterative processes of communication where what is learned and the possible ends to which those lessons are put are entirely open. In upstream policy engagement tools, citizens are invited to critique technological and policy prototypes in substantive and normative ways before any social roll-out is agreed (Wilsdon and Willis, 2004). Such early interactions are rare however. More commonly, public engagement is synonymous with tools such as consultation that fall some way short of a genuinely plural dialogue (Blanc and Ottimofiore, 2016).

One alternative is to facilitate reflexivity by building institutional architectures such as the experimental governance arrangements described by Sabel and Zeitlin (2008). The experimentalist architecture is essentially a network of multi-level governance units, such as the: European Commission, EU Member States, and industrial districts. In this network, there are policy problems for which no obvious solution is available at the centre. Thus, the centre's first task is to facilitate agreement on the objectives, for example via a system of indicators to measure progress. The second task is to encourage communication across the levels of the networks so that when a solution is found somewhere locally, by a certain constellation of actors, this solution can be validated via peer review within the network. If it passes validation, the solution can be imitated, adapted or hybridised by other actors in the multi-level network. Thus, the centre holds the measures and policy goals against which success can be gauged, but critically, lower-level policy actors have autonomy in how they achieve these policy ends and who in society they work with to get results. In exchange for this freedom, they participate in peer review exercises where they compare their approaches with European colleagues (Sabel and Zeitlin, 2010).

But what is learned in the context of reflexivity? Through open dialogue we learn about social norms (Checkel, 2005). This is a deep form of learning; by exploring and often re-defining social norms and the identities bound up within them, policy actors generate new consensus and new definitions of what is appropriate. They 
may even reframe their own identities - hence this deep learning is associated with paradigmatic policy change (Hall, 1993) and deutero learning (Argyris and Schön, 1978). Decision-makers learn about how to learn. What dialogue is good for and how to mainstream it into policy-making are the questions that follow. This is connected with ideals of Dewey's practical-moral deliberation (Sanderson, 2006), achieving the legitimacy of law through communicative rationality (Habermas, 1984) and the design of 'good' deliberative governance (Dryzek, 2010).

\section{Learning as by-product of bargaining}

When we turn to learning in the context of bargaining we enter the world of exchange, the craft of politics as compromise, give-and-take, exchange of resources, and 'making a deal'. To get into this mode, we need an issue that is eminently tractable and plural authority. 'Tractable' means that society (often public administration) has a repertoire of solutions, algorithms, or ways of doing things. Actors have to discover where the frontier of efficient bargaining lies, not how to cope with radical uncertainty. In terms of practical insights, understanding where a policy controversy is situated on this spectrum is crucial to success: one can pretend to bargain in a world of radical uncertainty, but it is like exchanging fake notes at the board game Monopoly ${ }^{\circledR}$ rather than making effective deals about what works.

Decision-makers, interest groups and civil society organisations need each other, they are inter-dependent. The mechanisms of exchange underpin interactions. Information is handled and changed during exchanges. Though decision-makers are not seeking truth (indeed they are bargaining), they select, acquire and trade information to inform their negotiating positions. This ultimately influences what they are willing to 'give' to competitors but it also generates a by-product: learning.

In policy contexts where stable policy communities dominate, interaction will be routinised. Here, decision-making risk is calculable and exchange mechanisms underpinned by actors' probability judgements derived from long-standing experiences. While these calculations will be adjusted and re-calibrated over time, the lessons generated may be thought of as little more as the realisation of expectations as opposed to any new discovery. In such circumstances, though it is never complete, transparency will be sufficient for actors to be able to make an accurate prediction of other parties' stances. On the other hand, where interactions are novel or one-off, or a new actor enters the arena, risk increases and transparency reduces. In this context of incomplete information, interactions will be marked more by negotiation and bet-hedging. Here, exchanges do not simply create lessons about the most efficient means to secure mutually beneficial outcomes. They may create new understandings about the issue entirely.

Our study on the Eurozone provides an instructive example (Dunlop and Radaelli, 2016: 117-19). Key episodes in the implementation of the European Semester fiscal surveillance system have been characterised by exchanges between Italy and France and the EU institutions. In one instance, Italy offered reforms in exchange of going beyond the deficit limits. France too played a similar game of offering offsets to the Commission, using the political leverage of a large member state to delay the reforms needed to exit the excessive deficit procedure. Here, we see a selective interpretation of policy and exchange mechanisms as the engine of learning about the boundaries of the negotiable. 
What is learning via bargaining good for, then? Essentially, lessons about preferences and the costs of cooperation. Taking preferences first, through bargaining and negotiation, policy-makers, pressure groups, decision-makers learn about the composition of preferences on an issue, the salient outcomes around which parties can coalesce and about breaking points - the red lines, so to speak. Decision-makers also learn about the cost of reaching agreements. Where policy problems are timesensitive, actors stand to lose if negotiation appears to be extending indefinitely and may radically adjust their stances to secure a quicker closure.

Bargaining in the end is good for certain things but not for others. Exchange generates important lessons both functionally and normatively. In terms of policy outcomes, ongoing negotiation uncovers the set of resource allocations required to ensure that no one gains at the expense of another. Once this is clear, decisionmakers can work through the possible trade-offs implied by the resulting narrow set of choices. There are also normative gains. In a society, the many processes of repeated exchange encapsulate Lindblom's Intelligence of Democracy (1965) whereby policy stability is generated by increased appreciation and understanding of rivals' positions. This partisan mutual adjustment (PMA) (Lindblom and Woodhouse, 1963) has normative properties as well as empirical leverage: it claims that a society based on preferences is better than a society based on knowledge or 'intellectual cogitation' (Dente, 2014) - the opposite of epistemic learning.

\section{Learning in hierarchies}

Our exploration of learning in hierarchies starts with the acknowledgement that rules-based systems can be formal or informal, contained in institutions or simply believed and trusted by a society. Indeed, what matters for a hierarchical rule to have power is that someone is obeyed. In some societies, family norms and standards set by communities like the village, the tribe or the neighbourhood are much more important than laws and regulations (Putnam, 1993). This leads us to frame learning with the metaphor of compliance.

Often we think of hierarchy as instructions, commands, and everything else that seems the antithesis of learning. What's hierarchy to do with learning, then? Consider this: over time actors learn about the scope of rules, their flexibility, and what happens when they are not followed. In a sense, this is the shadow of hierarchy: the range of social phenomena projected by the existence of a system of rules. It may be a set of court decisions, or more generally the nature of the legal system (Kelemen, 2010) to illuminate the scope of rules, or the attitude of inspectors. The rule per se is an incomplete contract that is defined over time via implementation.

Three powerful explanations capture the essence of the shadow of hierarchy. One is Scharpf's analysis of decisional blockages set at different levels of governance, like in federal systems or in the EU (1988). Another is the institutional grammar tool (Crawford and Ostrom, 1995). The third is the veto-players approach by Tsebelis (2002), which does not deal explicitly with hierarchy but offers a template to analyse decision-making systems. The joint-decision trap sheds light on hindrances and pathologies, as we explain below. The institutional grammar pins down the conditions that lead a rule to generate social behaviour, and is explicit on what happens if that type of behaviour does not appear. Veto-players theory provides yet another way to look at hindrances - we talk about this in the next section. 
Turning now to what this learning is good for, hierarchical rules are indispensable to organised societies. They define roles and stabilise expectations: an inspector has a role that is generally understood by companies and it is on the basis of expectations about this role that regulatory conversations between inspectors and firms take place (Blanc, 2016). Hierarchy also delivers on 'monitorability': some learning processes can be measured, compared, appraised because there is someone on top who sets the standards for monitoring compliance. Finally, this type of learning allows societies to sanction non-compliant behaviour. Sanctions and clear expectations about 'what happens if the rule is not followed' allow hierarchies to guide communities and societies. In international organisations, hierarchical learning is a common way to steer the behaviour of states and to allow the international society to affirm its norms.

\section{Lesson 2: Triggers and hindrances}

When learning 'works', it is because of some triggers that are activated - as we said earlier on, learning does not just 'happen'. But, learning processes can also be stymied, disrupted and de-railed. Thus, we need to look at both ends of the spectrum; the facilitating conditions as well as blocking factors. In this section, we consider triggers as well as hindrances.

\section{Triggering and hindering epistemic learning}

In epistemic contexts, an important learning trigger is the presence of statutory rights of consultation - meaning that an epistemic body ought to be consulted and listened to by policy-makers. A pluralistic approach to the use of expertise is another trigger. Some years ago, the European Commission launched a pan-European exercise on 'democratising expertise' with experts and policymakers. It culminated in the Liberatore report (2001). It is useful to recall the message of this report. For 'teaching' to be effective, expertise should be socially robust. This often implies a delicate balancing act between scientific quality and social, economic, and political preferences. Note that this trigger is not about 'majority voting in science', but rather about guaranteeing 'due process' in the way expertise is developed, used and communicated’ (Liberatore, 2001: 7).

For other triggers, we recall the findings of the literature on Europeanisation (Börzel and Risse, 2003). Here, we find that 'norm entrepreneurs' (Finnemore and Sikkink, 1998) and cooperative informal institutions facilitate the mission of epistemic communities. New lessons are not simply taught ex cathedra. They require alignment between epistemic norms, on the one hand, and shared understandings and structures of social meaning, on the other. Norm entrepreneurs actively seek this alignment via persuasion and advocacy.

Turning to hindrances, one problem in public policy controversies is the fragmentation of epistemic communities. We mentioned the case of the Mediterranean (Haas, 1990), but other policy domains are fraught with epistemic controversies. A good example is economic policy in the EU since the crisis of 2008 - with equally strong epistemic arguments for and against 'austerity' among economists. Obviously, without consensus on the lesson to be taught, there cannot be a clear message on which decision-makers can act. In some contexts, experts are re-framed as 'facilitator'. They do not contribute to the definition of the preferences of the learner, rather they 
simply help with know-how and technical responses to precise questions. Obviously, there isn't much epistemic enlightenment in these cases, although normatively it is justifiable that elected decision-makers remain in control of the objectives of learning. No matter how accurate and well-understood the lesson is, low policy capacity is always a powerful barrier (Dunlop, 2015; see Regonini, 2017).

\section{Enabling and disabling reflection}

There are two important triggers for reflexivity. One is institutional and concerns the governance architecture of deliberative, co-productive spaces. The design of committees, the role assigned to the chair, the style of interaction have causal effects on the presence or absence of the mechanism of dialogue crucial to reflexivity (Joerges and Neyer, 1997). More generally, Risse and Klein (2010) identified a full range of institutional scope conditions that trigger reflexivity in negotiations. Precisely they point to: institutional settings that support overlapping role identities; the transparency of negotiation settings with actors uncertain about the preferences of their audience (or, at the opposite, low transparency with certainty about the preference of the audience whose consent is required); and, norms and institutional procedures that privilege authority based on moral competence rather than formal power roles and hierarchy. Always at the aggregate level (organisations and political systems), institutions that promote and support socialisation are a strong pathway to reflexive learning.

The other trigger operates at the individual level. Here, what matters is the predisposition of the actors. We must assume that, at least at some point in time during the course of a policy process, actors have the predisposition to listen and to 'move' and therefore change their preferences. A good set of case studies is included in Frame Reflection, where reflexive learning is triggered only when actors are prepared to go beyond the 'dialogue of the deaf' (Schön and Rein, 1994). Repeated failure and a deterioration of the status quo push actors into this predisposition. In her Currency of Ideas, McNamara (1999) illustrates how repeated failure with a certain paradigm of monetary policy opened-up the minds of policy-makers to new policy paradigms and ultimately reflexivity.

As for hindrances, they operate in organisational and political cultures where there is not a deliberative tradition, and compromise is considered almost like losing one's honour and reputation. Further, the presence of genuinely incommensurable arguments makes deliberation either fake or covers the aggressive attempt to silence an argument - hence, it is domination (Pellizzoni, 2001). Thus, deliberation can degenerate into pathological or dysfunctional learning. For Karolewski (2011) the conventional deliberative methods used in the EU have their own dark side, particularly the false will formation and rational hijacking of deliberation. Provocatively, Lynn Sanders (1997) in Against Deliberation lists reasons, broadly speaking concerned with domination, why deliberation can violate democratic standards.

\section{Triggers and barriers to learning from bargaining}

For exchange to take place in bargaining, barriers to contract must be low. This trigger is not just about the absence of legal or technological barriers. It is also about the overall transparency of the negotiation settings and the circulation of information, so 
that actors can 'mutually adjust' on the basis of robust assumptions about what they exchange, with whom, and with what consequences. Partisan mutual adjustment is facilitated by Popper's (1945) open society with enforceable contracts and rule of law. Cultural, religious, technocratic dogmas limit learning via exchange.

If we move from the individual level to the organisational and social level, bargaining requires low barriers to aggregation of preferences. Eberlein and Radaelli (2010) distinguish between aggregation techniques and transformation techniques. Aggregation is particularly important for bargaining. It comes in two forms: one is issue-aggregation, the other is arena-aggregation. On the one hand, actors in organisations and political systems must be able to recombine issues to reach consensus and learn how to exploit cooperation. They should also be able to re-order issues temporarily, by exploiting delayed compensation and other classic ways of composing conflict. On the other hand, actors must be free to shift arenas and even to create a new arena, or break a complex conflict by allocating portions of the conflict to different arenas (Eberlein and Radaelli, 2010; for an empirical case see Radaelli and Kraemer, 2008 on the break-up of multi-dimensional conflict in different tax policy arenas in the EU).

The separation of procedures from substance reduces the friction in bargaining. If actors cannot successfully bargain on the outcome, they may find it easier to reach agreement on the procedure through which the outcome will be reached (Eberlein and Radaelli, 2010). It is the separation between procedure and substantive policy issues that is the trigger - not the procedure itself. There is another possible trigger based on de-coupling, that is, the separation between higher-level framework agreements and lower level policy issues. In this case the trigger is the possibility to agree on the framework agreement 'under the veil of vagueness' (Gibson and Goodwin, 1999, cited by Eberlein and Radaelli, 2010: 788).

Game theory suggests an important trigger - absent which we have the hindrance: exchange must be repeated, not one-shot, so that trust can be developed. The fuel of PMA, and more generally bargaining, is that the winners and losers are reshuffled in different iterations. No-one wants to play the same game if the result is always to be on the side of the losers. We illustrate empirically this point with the case of the negotiations on the excessive deficit procedure in the European Semester of the EU (Dunlop and Radaelli, 2016). The European Semester is an iterative mechanism of coordination of economic policy and promotion of structural reform. Bargaining deteriorates if there is ossification of winners and losers in the European Semester. Another hindrance is the low cost of defection, which makes partisan mutual adjustment and bargaining in general unstable.

\section{Triggering and hindering hierarchy}

It is not easy to pin down exactly the triggers for hierarchy. Studies of political culture suggest that habit-driven behaviour may best explain the variance between those who comply and those who violate. Such habits are underpinned by legitimacy, trust in authority, historical memories, and even deference as pre-conditions for political hierarchies to work (Dahl, 1971; Rothstein, 2000). Yet, this is only part of the story about the facilitating conditions. First, consider Tyler's famous question (2003): why do people pay taxes, obey and so on? Trust in authority is not a given; institutions must earn trust, and compliance must be socially deserved. 
Second, consider Chayes and Chayes (1993): deterrence, sanctions, enforcement and, in short, interests represent only one side of compliance. The other is (yet again) trust, identity, beliefs and, in short, norms. Thus, the trigger to compliance can be found in both the logic of interests and in the logic of norms. It depends on how interest constellations are composed once a rule is enforced, how norms have developed in a given society or policy setting.

As for hindrances, we can revert to what we said about Scharpf (1988) and Tsebelis (2002). Tsebelis is eminently interested in agenda-setting and decision-making. But think about veto players at the stage of implementation - Héritier et al (2001) provide a good empirical example about the implementation of EU road haulage regulations and the structure of truck drivers' associations as veto players. A high number of veto players at the implementation stage hinders compliance. Actors may learn dysfunctionally how not to comply if there are low costs in exercising veto players power. The number of implementation arenas (low or high) is in itself a veto player variable - if your policy has to go through many hoops the probability of not getting to destination is high. In short, the presence of a high number of veto players makes the chain of compliance murky. It reduces the probability that actors will in the end really learn something about rules and rules-following.

Scharpf (1988) instead draws our attention to the joint-decision trap in systems of multi-level governance. Under joint-decision trap conditions, the very possibility of agreeing on rules to be enforced hierarchically is stymied. These are institutional hindrances. However, the hindrance may occur at the policy level: not always is the solution known in advance, or at least agreed on the top level of the hierarchy. Learning from the top (Radaelli, 2008) is possible only if there is a relatively clear, unambiguous, agreed-upon solution that can then be pushed down the chain of hierarchy.

\section{Lesson 3: Watch out for learning pathologies}

Finally, we turn to dysfunctional learning, or pathologies (Dunlop, 2017a). Here social scientists who are sceptical of the romantic or benevolent bias of learning (Radaelli, 2009: 1147) will find their comfort zone.

\section{Dysfunctions of epistemic learning}

Epistemic actors may teach the 'wrong' lesson (Dunlop, 2017b). It is difficult for elected politicians to understand that science is not about the ultimate truth, but a process of conjectures and confutations. Science is about discovery, not dogma. In this sense, the lessons provided by epistemic teachers are neither contingent arguments ready to be demolished nor ever-present truths. Absent this understanding of science, the epistemic mechanism degenerates into the pathology of the dialogue of the deaf (Schön and Rein, 1994), in this case the lack of understanding between the world of science and the world of public opinion and public policy. Alternatively, groupthink often results in situations where the paradigm laid out by experts has captured policymakers' thinking (Janis, 1972). Finally, advocacy coalitions are good at mobilising counter-epistemic communities to politicise controversies and diluting the influence of experts and scientists (Rietig, 2018). 


\section{When reflexivity goes wrong}

One problem with reflexivity is scale: the mechanisms of dialogue can be triggered in small-scale deliberative fora. However, we do not know exactly how to couple deliberation in, say, mini-publics with collective, nationwide decision-making fora, for example legislative committees (for this discussion see Hendriks, 2016). The research of appropriate institutional mechanisms to link sites of deliberation to real-world public choice is still going on. In the meantime, de-coupling remains a pathology. Papadopoulos asks whether attempts to empower citizens and promote reflexivity locally matter for decision-making and institutional choice. Until they do, they may distract us from fundamental issues of democratic governance, especially if they suffer from bureaucratisation and disproportionately favour specialised, professional non-governmental organisations over ordinary citizens (Papadopoulos, 2013: 143). To conclude, de-coupling between the local and the systemic levels, lack of inclusiveness, experto-cratic self-selection and domination are the main warning lessons for practitioners willing to go down the road of reflexive learning.

\section{Dysfunctional bargaining}

Bargaining may end up in dysfunctional learning. This happens when actors have widely different endowments of resources. The scale is tilted from the very beginning and inertia results. Further, incremental changes and PMA do not allow constellations of actors to produce radical policy change. And, learning without transformation of preferences is not desirable when sticky preferences are exactly 'the' problem from a normative point of view. If a system needs new beliefs, re-conciliation of trade-offs, and radical policy innovation to come out of a crisis, it may not benefit from the type of learning generated by bargaining.

\section{Pathologies of hierarchy}

The pathologies of hierarchy are clear. A perfect shadow of hierarchy system with full compliance has no breathing spaces. It does not adapt to the environment. It requires accurate coupling with democratic institutions and standards, otherwise it violates democratic norms by veering towards authoritarianism. It stifles innovation and deep learning. Once actors have learned how to comply, there is no room to explore learning in other ways.

\section{Conclusions}

Drawing lessons from policy learning has major benefits. We have drawn three lessons: on the contexts, on triggers and hindrances, and on pathologies of learning. To conclude, we show that these lessons bring four advantages.

First, the findings point to a distinctive set of advantages of looking at policy processes with a learning lens. This is more important than establishing when some conjectures about learning are supported by what kind of evidence. Our article defies the traditional judgement of the value of a contribution. (Is the empirical material new? Does it successfully test this or that conjecture?) Rather, we make the case for novelty on the criteria set by the editors of this special issue. 
Second, we show that by opening up the peripheral vision on learning, and considering the four contexts in particular, social scientists can have a wider and more meaningful scientific conversation. Instead of collating data about who has tested what proposition about learning, we bring the findings on compliance, social norms, enforcement, Europeanisation, evidence-based policy and more to bear on learning. Ours is definitively not the standard review of the literature, but a synthesis that addresses the need of creating a wider social scientific audience for policy learning.

Turning to our other audience, the so-called practitioners, there are advantages too. Whether the problem is learning how to fight organised crime and corruption, or to re-launch growth in Europe or development in Africa, we suggest to start from capturing the context and then moving on to learning. This is equally important whether the objective is simply to exercise influence or to design a new process where a constellation of actors should reach some learning objectives over time. For social actors, our analysis shows when and how they should try to change the nature of the arena, or lobby for a re-design of the process - this lesson is often forgotten because social actors fight for a given policy objective, not for the parameters that define who does what and how in the policy process. As we said, it is important to understand the tone of the policy process in order to get learning right.

Third, triggers and hindrances add the fundamental scope conditions for learning to happen or not. Here our contribution shows to the audience of social scientists and the readership of practitioners that the general language of scope-conditions and middle-range theorising translates well into the world of policy learning. Some of the triggers and hindrances can be manipulated by design (like coupling a deliberative forum to public decision-making), others (like trust in institutions or attitudes towards science) are the product of historical memories and political culture. This is a lesson for those with the authority to design instruments and venues of learning (like consultation or a committee of enquiry) as well as for pressure groups. It is often the case that the problem is not learning per se, but activating the right mechanism or getting rid of the obstacles to learning.

The fourth advantage is to alert us that learning can be a failure. To demonstrate that learning can be dysfunctional brings back into the field of policy learning the classic orientation of many political scientists to focus on the difficulty of problem resolution, inertia, inefficiency, conflict and government failure. There are benefits for the audience of practitioners too. Private interests, non-governmental organisations and public managers themselves must be sufficiently critical in their engagement with learning. Depending on the context, they must be willing to unlearn lessons, push issues into arenas where learning types are different, or re-define their role (such as entrepreneur, teacher, and so on). To capture the strategic features of the context where learning takes place and whether the current approach to learning is functional or not is key.

Taken together, the lessons are useful to designers of public policy, but also to pressure groups and more generally non-state actors, including individual citizens who lobby directly by launching campaigns on specific issues (Alemanno, 2017). Typically, most of the attention is on the preferred solution and why learning does not take place, or takes place in a way that is not desirable. Our lessons direct us toward the profound insight of institutional analysis: learning responds to the tone of the interactions, to whether its mechanisms are activated or triggered or blocked, and to its quality: are we learning the good or bad lesson, for good or bad reason? 
Consequently, designers and social actors alike should get smarter, and direct their energy where it matters.

\section{Acknowledgements}

${ }^{1}$ Previous versions of this paper was presented at Lee Kwan Yew School of Public Policy (LKYSPP) 16-17 February 2017, UK Political Studies Association (PSA) annual conference, Glasgow, 6-8 April 2017; workshop on 'Practical Lessons from Policy Theories' University of Colorado, Denver, 14-16 May 2017; and European Consortium of Political Research (ECPR) annual conference, Oslo, 6-9 September 2017. We are grateful to all the participants of these events for their criticisms and comments. Biggest thanks must go to our special issue editors Paul Cairney and Chris Weible for all their imaginative work, our anonymous reviewers and the editorial team of Policy \& Politics for having faith in this innovative volume. The conceptual work was informed by two European Research Council (ERC) projects: Analysis of Learning in Regulatory Governance (ALREG) (grant \# 230267) and Procedural Tools for Effective Governance (PROTEGO) (grant \# 694632). The usual disclaimer applies.

\section{References}

Alemanno, A, 2017, Lobbying for Change: Find your voice and create a better society, London: Icon Books

Argyris, C, Schön, D, 1978, Organizational learning: A theory of action perspective, Reading, MA:Addison-Wesley

Blanc, F, 2016, From chasing violations to managing risks, PhD Thesis, Leiden: University of Leiden

Blanc, F, Ottimofiore, G, 2016, Consultation, in CA Dunlop, CM Radaelli (eds) Handbook of regulatory impact assessment, Cheltenham: Edward Elgar

Boehmer-Christiansen, S, 1994, Global climate protection policy: The limits of scientific advice. Parts 1 and 2, Global Environmental Change 4, 2, 140-59

Börzel, T, Risse, T, 2003, Conceptualising the domestic impact of Europe, in K Featherstone, CM Radaelli (eds) The politics of europeanization, Oxford: Oxford University Press

Boswell, J, 2018, What makes evidence-based policymaking such a useful myth? The case of NICE guidance on bariatric surgery in the UK, Governance 31, 2, 199-214

Cartwright, N, Hardie, J, 2012, Evidence-based policy, Oxford: Oxford University Press

Chayes, A, Chayes, AH, 1993, On compliance, International Organization 47, 2, 175-205

Checkel,JT, 2005, International institutions and socialization in Europe: Introduction and framework, International Organization 59, 4, 801-26

Crawford, S, Ostrom, E, 1995, A grammar of institutions, American Political Science Review 89, 3, 582-600

Cross, MKD, 2013, Rethinking epistemic communities twenty years later, Review of International Studies 39, 1, 137-60

Dahl, RA, 1971, Polyarchy: Participation and opposition, New Haven, CT:Yale University Press

Dente, B, 2014, Understanding policy decisions, New York, NY: Springer

Dewey, J, 1927, The public and its problems, New York, NY: Holt, 2012

Dunlop, CA, 2010, Epistemic communities and two goals of delegation: Hormone growth promoters in the European Union, Science and Public Policy, 37, 3, 205-217 
Dunlop, CA, 2014, The possible experts: How epistemic communities negotiate barriers to knowledge use in ecosystems services policy, Environment and Planning C- Government Policy 32, 2, 208-28

Dunlop, CA, 2015, Organizational political capacity as learning, Politics and Society $34,3,259-70$

Dunlop, CA, 2017a, Policy learning and policy failure: Definitions, dimensions and intersections, Policy \& Politics 45, 1, 19-37

Dunlop, CA, 2017b, Pathologies of policy learning: What are they and how do they contribute to policy failure?, Policy \& Politics 45, 1, 3-18

Dunlop, CA, 2017c, Epistemic communities and the irony of policy learning, Policy and Society, 36, 2, 215-32

Dunlop, CA, Radaelli, CM, 2013, Systematizing policy learning: From monolith to dimensions, Political Studies 61, 3, 599-619

Dunlop, CA, Radaelli, CM, 2016, Policy learning in the Eurozone crisis: Modes, power and functionality, Policy Sciences 49, 2, 107-24

Dunlop, CA, Radaelli, CM, Trein, JP, 2018, Introduction: The family tree of policy learning, in CA Dunlop, CM Radaelli (eds) Learning in public policy: Analysis, modes and outcomes, Basingstoke: Palgrave

Dryzek, JS, 2010, Foundations and frontiers of deliberative governance, Oxford: Oxford University Press

Eberlein B, Radaelli, CM, 2010, Mechanisms of conflict management in EU regulatory policy, Public Administration 88, 3, 782-99

Finnemore, M, Sikkink, K, 1998, International norm dynamics and political change, International Organization 52, 4, 887-917

Freeman, R, 2006, Learning in public policy, in M Moran, M Rein, RE Goodin (eds) Oxford handbook of public policy, Oxford: Oxford University Press

Goyal, N, Howlett, M, 2018, Lessons learned and not learned: Bibliometric analysis of policy learning, in CA Dunlop, CM Radaelli (eds) Learning in public policy: Analysis, modes and outcomes, Basingstoke: Palgrave

Haas, PM, 1990, Saving the Mediterranean: The politics of international environmental cooperation, New York, NY: Columbia University Press

Habermas, J, 1984, The theory of communicative action volume 1, Boston, MA:Beacon Press

Hall, PA, 1993, Policy paradigms, social learning and the state:The case of economic policy-making in Britain, Comparative Politics 25, 3, 275-96

Heikkila, T, Gerlak, AK, 2013, Building a conceptual approach to collective learning: Lessons for public policy scholars, Policy Studies Journal 41, 3, 484-511

Hendriks, CM, 2016, Coupling citizens and elites in deliberative systems:The role of institutional design, European Journal of Political Research 55, 1, 43-60

Héritier, A, Kerwer, D, Knill, C, Lehmkuhl, D, Teutsch, M, Douillet, A-C, 2001, Differential Europe: The European Union impact on national policymaking, London: Rowman \& Littlefield

Janis, IL, 1972, Victims of groupthink, New York: Houghton Mifflin

Jenkins-Smith, HC, 1990, Democratic politics and policy analysis, Pacific Grove, CA: Brooks/Cole

Joerges, C, Neyer,J, 1997, From intergovernmental bargaining to deliberative political processes, European Law Journal 3, 3, 273-99

Karolewski, IP, 2011, Pathologies of deliberation in the EU, European Law Journal $17,1,66-79$ 
Kelemen, RD, 2010, Globalising European Union environmental policy, Journal of European Public Policy 17, 3, 335-49

Liberatore,A, 2001, Report of the working group on democratising expertise and establishing scientific reference systems, Brussels: European Commission

Lindblom, CE, 1965, The intelligence of democracy, New York: The Free Press

Lindblom, CE, Woodhouse, EJ, 1963, The policy-making process, Engelwood Cliffs, NJ: Prentice Hall

McAdam, D, Tarrow, S, Tilly, C, 2001, Dynamics of contention, Cambridge, MA: Cambridge University Press

McNamara, KR, 1999, The currency of ideas: Monetary politics in the European Union, Ithaca, NY: Cornell University Press

Majone, G, 1989, Evidence, argument, and persuasion in the policy process, New Haven, CT:Yale University Press

Moyson, S, Scholten, P, Weible C M, 2017, Policy learning and policy change: Theorizing their relations from different perspectives, Policy and Society, 36, 2, 161-77

Novak, JD, Gowin, DB, 1984, Learning how to learn, Cambridge, MA: Cambridge University Press

Nutley, SM, Walter, I, Davies, HTO, 2007, Using evidence: How research can inform public services, Bristol: The Policy Press

Papadopoulos, Y, 2013, Democracy in crisis? Politics, governance and policy, Basingstoke: Palgrave Macmillan

Patton MQ, 1997, Utilization-focussed evaluation, Thousand Oaks, CA: Sage

Pellizzoni, L, 2001, The myth of the best argument, The British Journal of Sociology $52,1,59-86$

Popper, KR, 1945, The open society and its enemies volume 2, London: Routledge

Putnam, RD, 1993, Making democracy work, Princeton, NJ: Princeton University Press

Radaelli, CM, 1997, The politics of corporate taxation in the European Union: Knowledge and international policy agendas, London: Routledge

Radaelli, CM, 2008, Europeanization, policy learning and new modes of governance, Journal of Comparative Policy Analysis 10, 3, 239-54

Radaelli, CM, 2009, Measuring policy learning: Regulatory impact assessment in Europe, Journal European Public Policy, 16, 8, 1145-64

Radaelli, CM, Kraemer US, 2008, Governance areas in EU direct tax policy, Journal of Common Market Studies 46, 2, 315-36

Regonini, G, 2017, Governmentabilities without policy capacity, Policy Sciences 50, $2,163-78$

Rietig, K, 2018, The link between contested knowledge, beliefs and learning in European climate governance: From consensus to conflict in reforming biofuels policy, Policy Studies Journal 46, 1, 137-159

Risse, T, Klein, M, 2010, Deliberation in negotiations, Journal of European Public Policy $17,5,708-26$

Rothstein, B, 2000,Trust, social dilemmas and collective memories, Journal of Theoretical Politics 12, 4, 477-501

Sabel, C, Zeitlin, J, 2008, Learning from difference: The new architecture of experimentalist governance in the European Union, European Law Journal 14, 3, 271-327

Sabel, C, Zeitlin, J, 2010, Experimentalist governance in the European Union, Oxford: Oxford University Press 
Sanders, L, 1997, Against deliberation, Political Theory 25, 3, 347-76

Sanderson, I, 2006, Complexity, 'practical rationality' and evidence-based policy making, Policy and Politics 34, 1, 115-32

Scharpf, F, 1988, The joint decision trap: Lessons from German federalism and European integration, Public Administration 66, 3, 239-78

Schön, DA, Rein, M, 1994, Frame reflection: Toward the resolution of intractable policy controversies, New York, NY: Basic Books

Torgerson, D, 1992, Priest and jester in the policy sciences: Developing the focus of inquiry, Policy Sciences 25, 3, 225-35

Tsebelis, G, 2002, Veto players: How political institutions work, Princeton, NJ: Princeton University Press

Tyler, TR, 2003, Procedural justice, legitimacy, and the effective rule of law, Crime and Justice 30, 283-357

Wilsdon, J, Willis, R, 2004, See-through science, London: Demos 